\title{
GESLAGSVERSKILLE IN DIE OUDITIEWE ONTLOKTE POTENSIAAL VAN DIE BREIN
}

\author{
ANITA D. STUART \\ adst@lw.rau.ac.za \\ Departement Sielkunde \\ Universiteit van Johannesburg
}

\begin{abstract}
Gender differences in the auditory evoked potential of the brain. Based on literature indications of an association between temperament characteristics and the evoked potential of the brain, and indications of gender differences in certain temperament traits, the purpose of this study was to ascertain whether evoked responses also differentiated between the genders. A sample of 81 male and 210 female students was randomly selected. Two auditory evoked potential procedures were applied. The results indicated statistically significant differences in evoked potential responses between the genders. The results are interpreted against the background of sensory and neurological sources of the evoked potential responses and linked to the neurophysiological foundations of temperament.
\end{abstract}

\section{OPSOMMING}

Gegrond op aanduidings in die literatuur van 'n assosiasie tussen temperamentskenmerke en die ontlokte potensiaal van die brein, sowel as aanduidings van geslagsverskille in sekere temperamentstrekke, was die doel van die huidige studie om te bepaal of ontloktepotensiaal-response ook tussen die geslagte onderskei. 'n Steekproef van 81 manlike en 210 vroulike studente is ewekansig geselekteer. Twee ouditiewe ontloktepotensiaal-prosedures is toegepas. Die resultate het op statisties beduidende verskille tussen die geslagte gedui. Die bevindinge word teen die agtergrond van die sensoriese en neurologiese oorsprong van ontloktepotensiaal-response geinterpreteer en verbind aan die neurofisiologiese verankering van temperament.

Key words

Evoked potentials, temperament, gender differences

\section{SYNOPSIS}

The purpose of the study was to investigate whether there are gender differences in the evoked potentials of the brain. The rationale for the study was based on evidence in the literature of an association between evoked potential responses and certain neurophysiologically anchored temperament characteristics, and also on literature indications of gender differences in these temperament dimensions. The research question thus was whether gender differences manifest in the evoked potential responses which are associated with these temperament dimensions.The evoked potentials which were investigated were the five latency and the five amplitude measures of the auditory brainstem response, the two latency measures (N1 and P2) and one amplitude measure (N1-P2) of the auditory middle latency response at $35 \mathrm{~dB}$ and also at $80 \mathrm{~dB}$, and the cortical augmenting-reducing phenomenon evoked by variations in stimulus intensities ( $35 \mathrm{~dB}$ and $80 \mathrm{~dB})$ after which the $35 \mathrm{~dB}$ response was deducted from the $80 \mathrm{db}$ response for statistical analysis. A sample of 291 students (81 males and 210 females) aged 17 to 22 years, randomly selected from a statistical population of 492, completed the neuropsychological battery. Hotelling's $T^{2}$-test was used to ascertain whether the vector of averages of the two groups differed statistically significantly or not. Student's t-test and the F-test were used to test the significance of differences between the means and the variances of the two groups respectively. The results of the study indicated statistically significant gender differences with regard to all the latency measures and two of the amplitude measures (III and $I V)$ of the brainstem response. The males showed longer latencies and lower amplitudes than the females. Regarding the middle latency evoked response measures gender differences manifested in the 35db N1-P2 amplitude and in the 80dB N1 latency. The males showed a lower amplitude and a longer latency than the females. No final conclusions can be made regarding gender differences in the augmenting-reducing response. The results are interpreted against a background of literature indications regarding the sensory and neurological sources of the evoked responses, and linked to findings in the literature regarding the neuro-sensory foundations of temperament.
In die bedryf is dit reeds 'n cliché om te verwys na die 'regte persoon vir die regte taak'. Die korrekte plasing van werknemers kan produktiwiteit verhoog en een van die belangrikste oorwegings by die keuse van ' $n$ werknemer vir ' $n$ gegewe taak is die temperament van die persoon. Verskeie teoretici en navorsers in sowel Westerse as Russies-Poolse Sielkundige denksisteme aanvaar dat temperamentstrekke meer is as omgewingsgemotiveerde gedragsmanifestasies en dat temperament inderdaad 'n diep neurofisiologiese verankering het (byvoorbeeld die teorieë van Pavlov, Teplov, Nebylitsyn, Strelau, Gray, Allport, Eysenck, Zuckerman en so meer). Die omvang en diepte van die fisiologiese en/of neurologiese wortels van menslike gedrag is egter steeds 'n onderwerp van vele studies en ook vele teenstrydighede.

Een van die navorsingsterreine rakende die neurofisiologiese verankering van temperament wat in die afgelope tyd heelwat belangstelling gewek het, is die elektriese aktiwiteit van die brein. Spesifiek relevant vir die huidige navorsing is die ontlokte potensiaal van die brein.

Beskrywing van ontlokte breinpotensiaal

Die ontlokte potensiaal van die brein verwys na elektriese breinaktiwiteit wat deur veelvuldige stimulasie van een van die modaliteite, byvoorbeeld die visuele of ouditiewe reseptore, ontlok word. Al die stimulusgebonde breingolwe word gesommeer en die gemiddelde breingolf rekenaarmatig bereken. Vir die doeleindes van die huidige navorsing is slegs die ouditiewe modalitieit ter sprake. Die ouditiewe ontloktepotensiaalgolfvorms word in die literatuur aan die hand van vroeë- (breinstam-), middel- en laatlatensiekomponente beskryf (Chiappa 1983; Loveless, 1983). Die laatlatensiekomponente hou verband met kognitiewe vaardighede, wat buite die bestek van die huidige navorsing val. Slegs die vroeë- en middellatensiekomponente word bespreek aangesien hierdie komponente in wetenskaplike geskrifte met temperament geassosieer word.

Die vroeë ouditiewe ontlokte breinstampotensiaal (OBR) se latensies I tot $\mathrm{V}$ en amplitudes I tot $\mathrm{V}$, wat minder as $30 \mathrm{~ms}$ na die stimulus verskyn (Chiappa, 1983), toon 'n kopvelverspreiding 
wat op 'n oorsprong in die ouditiewe senubane en breinstamnuklëi dui. Volgens Davis en Owen (1985) is die generatorgebied van Golf I van die ontlokte breinstampotensiaal die ouditiewe senuwee. Golwe II en III ontstaan in die kogleêre kern en die superior olyfkompleks respektiewelik, terwyl Golf IV en $\mathrm{V}$ in die laterale leminiskus en die inferior colliculus ontstaan (Davis \& Owen, 1985; Moller, Moller \& Jannetta,1982).

Die ouditiewe ontlokte middellatensiepotensiaal (OMR), wat deur die N1- en P2-latensies en die N1-P2-amplitude gekenmerk word, verskyn tussen 10 en $75 \mathrm{~ms}$ na die stimulus en het 'n wye distribusie wat suggereer dat hierdie komponente in die diep strukture van die brein ontstaan (Chiappa,1983; Hannay, 1986; Loveless, 1983). Buchwald (1990) is van mening dat cholinergiese aktiwiteit in die pons-, tegmentale en talamiese gebiede die generatorgebied van Golf P1 is. Dit is interessant dat die P1potensiaal afwesig is of beduidend verklein is by pasiënte met Alzheimer se siekte.

Soos in die volgende afdeling aangedui word, assosieer navorsers die verskillende vroeë- en middellatensiekomponente (OBR- en OMR-komponente) met verskillende gedrags- en temperamentsdimensies. Hierdie assosiasie verteenwoordig moontlik die voorheenvermelde neurofisiologiese wortels van menslike temperament.

\section{Ontlokte potensiaal en temperamentkenmerke}

Stelmack en Wilson (1982) het navorsing gedoen oor die verwantskap tussen introversie-ekstroversie en die ouditiewe ontlokte breinstampotensiaal. Hulle het langer Golf I- en Golf IV-latensies by vroue met hoë ekstroversie- teenoor lae ekstroversie-tellings by hoë stimulusintensiteite gevind. Geen amplitudeverskille is gevind nie. Bullock en Gilliland (1993) kon hierdie verskille bevestig. Woodward et al. (2001) het ook gevind dat volwasse introverte korter latensies in sekere komponente van die ouditiewe breinstamrespons toon as ekstroverte. Teenstrydig met laasgenoemde het Bar-Haim (2003) met 'n klein steekproef kinders gewerk en bevind dat laer amplitudes en stadiger latensies geassosieer word met sosiaalteruggetrokke kinders. Campbell, Baribeau-Brown en Braun (1981) kon geen verskille tussen persone met lae en hoë ekstroversie-tellings ten opsigte van die OBR vind nie. Geen van hierdie studies het die geslagte se response vergelyk nie.

Met verwysing na die N1- en P2-middellatensie ontloktepotensiaal-response het 'n aantal navorsingstudies (byvoorbeeld Stelmack en Michaud-Achorn, 1985) gevind dat introverte hoër ontlokte potensiaal-amplitudes toon as ekstroverte. 'n Eksplosiewe temperament is deur Bars (2001) geassosieer met hoë-amplitude P100-response.

Die middellatensie kortikale vergroting-verkleiningrespons word in die literatuur geassosieer met sensasiesoekende gedrag. Met toename in stimulusintensiteit toon sommige persone hoër amplitudes (kortikale vergroting) en ander laer amplitudes (kortikale verkleining). Zuckerman (2005) en Steinberg, Rosen en Risberg (1988) het met 'n Cz-elektrodeplasing byvoorbeeld gevind dat persone met hoë disinhibisie-tellings op die Sensasiesoekeskaal, vergroting van N1-P2-amplitudes toon by toenemende visuele intensiteite, wat nie by persone met lae disinhibisie-tellings voorgekom het nie. Von Knorring (1981) het dieselfde bevinding kon toon by plasing van die elektrode op $\mathrm{Oz}$. Hegerl, Prochno, Ulrich en Muller-Oerlinghausen (1989) kon geen verwantskap tussen sensasiesoeke en kortikale vergroting of verkleining demonstreer nie. Hulle het wel hemisferiese differensiasie by die lae sensasiesoekers gevind (langer latensies oor die linkerhemisfeer) wat nie by hoë sensasiesoekers voorgekom het nie.

Die neurofisiologiese en biochemiese verankering van gedrag/temperament word ondersteun deur navorsing wat verbande tussen psigopatologie en kortikale vergrotingverkleining kon aandui. Volgens Zuckerman $(1990,1991)$ neig persone van beide geslagte met bipolêre versteuring tot kortikale vergrotingresponse wanneer sowel maniese as depressiewe fases ervaar word. Hierdie respons word toegeskryf aan disfunksie van die beskermende inhiberingsmeganisme. Lithium verander die patroon na 'n verkleiningsrespons. Hermann (2002), Fallgatter (1998) en andere het gevind dat vergroting van die ontlokte respons voorkom by alkoholiste.

Dit blyk dat ook diere individuele verskille ten opsigte van kortikale vergroting-verkleining toon. Saxton, Siegel en Lukas (1987) kon byvoorbeeld aantoon dat katte wat kortikale vergroting demonstreer, aktief, aggressief, sosiaal en responsief ten opsigte van nuwe stimuli is. Katte wat kortikale verkleining demonstreer skram weg van nuwe stimuli en vermy sosiale omgang.

Die resultate van studies wat die verbande tussen ontloktepotensiaal-response en sekere temperamentsdimensies ondersoek, is nie altyd konsekwent nie en skep geen duidelike beeld nie. Sommige studies gebruik visuele, en ander ouditiewe ontlokte potensiaal, elektrodeplasings wissel, en verskille in stimulusintensiteite en interstimulusintervalle verdoesel die bevindinge. Verder word daar selde inligting oor die fisiese laboratoriumveranderlikes wat bevindinge kan kontamineer, gerapporteer. In baie studies word omvattende afleidings gemaak op grond van klein steekproewe. Die konstrukgeldigheid van die vergroting-verkleiningsfenomeen word deur Carillo-de-la-Pena (1992), Connolly (1986) en Connolly en Gruzelier (1982) betwyfel as gevolg van die gebrek aan intermodale konsekwentheid, waardeur die sentrale invoerreguleringsmeganismes wat met sensasiesoeke geassosieer word bevraagteken word.

Desnieteenstaande het Robinson (2001) in sy uitgebreide navorsing oor die assosiasie tussen ontloktepotensiaal-response en temperamenteienskappe die verbande telkemale kon bevestig en skryf individuele verskille in temperament en in ontloktepotensiaal-response toe aan verskille in die talamokortikale inhibisie- en opwekkingsisteem in die breinstam.

\section{Geslagsverskille in temperament}

In die literatuur is daar relatief sterk aanduidings van geslagsverskille in temperament. Dragotinovich (1987), Zuckerman (2005) en Stuart (1994) het byvoorbeeld gevind dat mans statisties beduidend hoër tellings op sensasiesoekeskale en verbandhoudende temperamentskale (byvoorbeeld die Vando-stimulusvergroting-verkleiningskaal) behaal as dames. Die verskille word toegeskryf aan differensiële werking van die gonodale hormone en geslagsverskille in MAOvlakke (Berenbaum \& Hines, 1992; Rothbart, Ahadi \& Evans, 2000). Sermat en Smyth (1973) rapporteer statisties beduidend meer ekstrovertiewe gedrag by vrouens as by mans. Vrouens het ook 'n groter affiliasiebehoefte en toon meer interpersoonlike betrokkenheid as mans. Torgensen (1985) het gevind dat meisies meer sosiaal as seuns is op sesjarige ouderdom en Benenson (1993) sowel as Gleason, Gower en Hohmann (2005) bevestig verskille in sosiale ekstroversie tussen seuns en dogters.

\section{Geslagsverskille in ontloktepotensiaal-response}

Gegee die bevindinge in die literatuur van enersyds ' $n$ assosiasie tussen die ontlokte potensiaal van die brein en temperament, en andersyds aanduidings van geslagsverskille in temperament, volg dit dat daar by die opnames van die ontlokte potensiaal van die brein, ook geslagsverskille mag blyk. In hierdie opsig is daar egter ' $n$ besondere leemte in die literatuur aangesien die meeste studies oor hierdie onderwerp nie tussen die geslagte in hulle navorsingsontwerpe onderskei nie. Enkele studies bestaan wel wat geslagsverskille aandui: Dehan en Jerger (1990), Shearer, Emmerson en Dustman (1992), Michalewski, Thompson, Patterson, Bowman en Litzelman (1980) en Sturzebecher en Werbs (1987) het geslagsverskille in die amplitudes van die ouditiewe breinstamrespons gevind, waar die vroulike proefpersone korter latensies en hoër amplitudes as mans 
gedemonstreer het. Met verwysing na visuele ontloktepotensiaalresponse het Fein en Brown (1987) beduidend hoër amplitudes by dames as by mans gevind.

Studies van drie dekades tevore het geslagsverskille in kortikale vergroting-verkleining aangedui (Buchsbaum, Henkin \& Christiansen, 1974). Dames het kortikale vergrotingresponse gehad terwyl mans meer geneig was tot kortikale verkleining. Die rigting van laasgenoemde geslagsverskille is egter teenstrydig met die bevinding dat mans meer sensasiesoekend is as dames. Die outeurs verduidelik ook nie die diskrepans nie. In dieselfde dekade het Gershon en Buchsbaum (1977) geen geslagsverskille in kortikale vergroting-verkleining in 'n Israeliese steekproef kon vind nie. Geen resente navorsing oor geslagsverskille in kortikale vergroting-verkleining kon gevind word nie.

Sommige van die genoemde studies wat geslagsverskille ten opsigte van ontloktepotensiaal-komponente demonstreer, is oudiologies en optalmologies van aard en verduidelik nie die moontlike redes vir die verskille nie, wat op 'n verdere leemte in die literatuur dui.

Ter opsomming van enkele literatuuraanduidings blyk dit dat:

- ektroverte 'n geneigdheid toon tot langer breinstamlatensies en hoër middellatensie-amplitudes, teenoor

- introverte wat geneig is tot korter breinstamlatensies,

- en dat avontuursoeke, aktiwiteit, aggressie en sosialiteit ten minste in sommige studies met vergrotingsresponse geassosieer word

Ten opsigte van geslagsverskille in temperament blyk dit dat:

- mans hoër sensasiesoeketellings behaal, teenoor

- dames, wat hoër ekstroversie en affiliasie toon.

Ten opsigte van geslagsverskille in ontloktepotensiaal-response blyk dit dat slegs enkele studies vir geslag kontroleer en dat:

- dames korter latensies en hoër amplitudes as mans demonstreer,

- dat dames meer geneig is tot kortikale vergrotingresponse,

- teenoor mans wat meer geneig is tot kortikale verkleiningresponse.

Die uiteenlopendheid van navorsingsbevindinge, studies wat teenstrydige resultate rapporteer en die metodologiese probleme wat soms ter sprake is word weereens beklemtoon.

\section{Navorsingsvraag en doel van studie}

Die bestaande navorsingsresultate ten opsigte van die verwantskappe tussen sekere temperamensdimensies en ontloktepotensiaal-response, sowel as bevindinge rakende geslagsverskille in temperament, het as teoretiese agtergrond vir die huidige studie gedien. Die beperkte en teenstrydige bevindinge rakende geslagsverskille in die ontloktepotensiaal-komponente het die basis vir die navorsingvraag gevorm. Die oorkoepelende navorsingsvraag vir die huidige studie was soos volg:

Kan robuuste en verifieerbare ouditiewe ontloktepotensiaalkomponente onder strenggekontroleerde laboratoriumtoestande geidentifiseer word wat latensie- en/of amplitudeverskille en/of kortikale vergroting- of verkleiningverskille tussen manlike en vroulike proefpersone demonstreer?

Die doel van die studie spruit voort uit die navorsingsvraag en wou bepaal of daar geslagsverskille is in die volgende ontloktepotensiaal-response:

- Die vyf latensies en die vyf amplitudes van die ouditiewe ontlokte breinstamresponse (OBR)

- Die twee latensies en een amplitude van die ouditiewe middellatensie-response (OMR) by 35dB-stimulusintensiteit en ook by $80 \mathrm{~dB}$-stimulusintensiteit.

- Die 35db OMR N1-latensie afgetrek van die 80dB OMR N1-latensie, die 35dB OMR P2-latensie afgetrek van die 80dB OMR P2-latensie, en die 35dB OMR N1-P2- amplitude afgetrek van die 80dB OMR N1-P2-amplitude (om geslagsverskille in kortikale vergroting-verkleining te ondersoek).

\section{NAVORSINGSONTWERP}

\section{Seleksie van proefpersone}

Die steekproef vir die huidige ex post facto studie het uit eerstejaarstudente in die gedragswetenskappe bestaan. Oor 'n tydperk van twee jaar is ' $n$ groot aantal deelnemers individueel op nie-sistematiese wyse gekontak en afsprake gemaak om by die neurosielkundelaboratorium aan te meld vir toetsing. 'n Ewekansige seleksie is sover moontlik verseker. Sekere faktore het daartoe gelei dat die oorspronklike aantal proefpersone van 492 verminder het tot 291: Slegs persone tussen 17 en 22 jaar is ingesluit om te kontroleer vir breinrypingseffekte; persone met epilepsie, gehoorsgestremdheid, en enige vorm van breinskade is uitgesluit om ongekontamineerde elektrofisiologiese metings te verseker; persone met onvolledige elektrofisiologiese verslae is uitgesluit; en alle onduidelike elektrofisiologiese verslae is ter syde gestel. Die finale steekproef het uit 81 mans en 210 dames bestaan. Weens die relatiewe homogeniteit van die studentebevolking ten opsigte van intelligensie is aanvaar dat geen groot intelligensieverskille sal voorkom wat 'n noemenswaardige effek op die elektrofisiologiese metings sal hê nie. Belangstelling is nie as ' $n$ veranderlike in die huidige studie in ag geneem nie omdat die spektrum van belangstellings in ' $n$ groot steekproef potensieel baie breed is en spesifieke belangstellings mekaar sal uitkanselleer. Die prosedures is in die proefpersoon se voorkeurtaal (Afrikaans of Engels) aan hom/haar verduidelik. Geen in- of uitsluitingskriterium rakende rasseverteenwoordiging is gestel nie dog die finale steekproef het oorwegend uit blanke persone bestaan (97\%).

\section{Data-insameling en prosedure}

Die Nicolet Pathfinder II in die klankdigte neuropsigologielaboratorium van 'n universiteit is gebruik om twee ontloktepotensiaal-prosedures toe te pas. Die twee prosedures het opnames van die ouditiewe breinstamrespons (OBR) en opnames van die verteks ouditiewe middellatensierespons (OMR) by twee verskillende stimulusintensiteite behels. Toetlinge is oor die prosedure ingelig en uitgenooi om te ontspan aangesien hulle slegs moes luister en geen respons vereis is nie.

Opname van die ouditiewe breinstamrespons (OBR)

Die Pathfinder II is opgestel en die bedryfstelsel gelaai volgens die prosedure wat in die handleiding beskryf word. Die geselekteerde elektrodes vir hierdie protokol is $\mathrm{Cz}$ (verteks) verwys na M1 (linkermastoïde) en die grond na Fpz (voorkop) volgens die tien-twintig sisteem (Jasper, 1958). Die NIC SM200 (Fisiologiese Versterker) se elektrodeskakelaar is op Kanaal I gestel en die weerstand (impedansie) getoets ( $<2$ kilo-ohms). Die posisies van die paneelskakelaars van die Pathfinder II, die opnameprosedure en die komponentbepaling is volgens standaardinstruksies in die handleiding uitgevoer. Hiervolgens is die totale ontledingstyd $10 \mathrm{~ms}$ en die aantal stimulusherhalings 2000, die stimulusduur is 100 mikrosekondes en die tempo van stimulusaanbieding 11.1/sekondes. Die klikstimulus se intensiteitsvlak is $75 \mathrm{~dB}$. Slegs die linkeroor is gestimuleer. Volgens algemene praktyk word die OBR opgeneem tussen die verteks en die oor ipsilateraal tot die stimulus.

Die stereofoniese oorfone (Telephonics TDH - 39P/29600001) is in die korrekte posisie oor die kop van die toetsling geplaas en die beligting versag. Deur die korrekte skakelaars aan te skakel is die stimuli voorts outomaties aan die linkeroor aangebied en die gevolglike ontlokte breinstampotensiaal opgeneem in die Pathfinder II se geheueblok A1. Sodra 2000 herhalings voltooi is, hou die opnames outomaties op. Alle artefakte word outomaties verwerp. Deur dieselfde prosedure te volg word 'n 
tweede opname gemaak en in 'n tweede geheueblok A2 opgeneem, sodat die repliseerbaarheid en dus die betroubaarheid van die opname verseker kan word. Die golwe word nou rekenaarmatig oormekaar gelê om vergelyking te fasiliteer. Indien die opname en die repliseerbaarheid daarvan bevredigend is, word die opname op 'n geformateerde disket gestoor. Geen meting is aanvaar voordat die betroubaarheid van die golwe bevestig is nie: indien die replisering onbevredigend is, word die prosedure herhaal totdat betroubare golfvorms verkry is. 'n Lêernaam word outomaties aangevra. Die naam vir elke proefpersoon was telkens die eerste drie letters van sy van gevolg deur die prosedure se naam, byvoorbeeld SCH vir Schoeman, gevolg deur OBR vir ouditiewe breinstamrespons, dus SCHOBR.

Om die OBR-komponente te bepaal en te benoem is 'n titellêer vooraf vir die OBR-golfvorms geskep met ruimte vir die eerste vyf komponente se latensies en amplitudes (dus tien subtellings).

Opname van die ouditiewe middellatensie-respons (OMR)

Die ouditiewe middellatensie-respons is by twee verskillende stimulusintensiteite opgeneem te wete $35 \mathrm{~dB}$ en $80 \mathrm{~dB}$. Die geselekteerde elektrodes is $\mathrm{Cz}$ verwys na Fpz en die grond is M1. Die elektrode-weerstand is gehandhaaf by $<2$ kilo-ohms. Klankstimuli in plaas van klikke is vir hierdie opname gebruik. Albei ore in plaas van net die linkeroor is gestimuleer. Soos in die geval van die OBR word die paneelskakelaarposisies, die OMR-golfopname en die komponentbepaling en -benoeming volgens standaardprodedures soos beskryf in die Pathfinder IIhandleiding gevolg. Hiervolgens is die totale ontledingstyd $500 \mathrm{~ms}$ en die aantal stimulusherhalings 60 . Die stimulusduur is 100 mikrosekondes en die tempo van aanbieding 0.6 /sekondes. Vir beide ore was die stimulusintensiteit $35 \mathrm{~dB}$ vir die eerste opname en $80 \mathrm{~dB}$ vir die tweede opname.

Die oorfone is weer eens in die regte posisie oor die toetsling se kop geplaas, die weerstand is weer eens gekontroleer waarna die opname begin is deur die $35 \mathrm{~dB}$ klankintensiteit te selekteer. Nadat 60 artefak-vrye herhalings voltooi is en in geheueblok A1 gestoor is, word die prosedure in die tweede geheueblok A2 herhaal. Die golwe word oormekaar gelê en indien die twee golfopnames ooreenstem, word die resultaat as betroubaar aanvaar. Indien die golwe nie bevredigend gerepliseer is nie, word die prosedure herhaal. Dieselfde proses word nou gevolg by 'n klankintensiteit van $80 \mathrm{~dB}$. Die twee golwe wat deur die samevoeging van vier golwe ontstaan, word in 'n lêer gestoor met die eerste drie letters van die persoon se naam gevolg deur die prosedurenaam (byvoorbeeld SCHOMR vir Schoeman, ouditiewe middellatensie-respons)

'n Titellêer is vir die OMR geskep met ruimte vir die twee golwe se N1- en P2-latensies en die N1-P2-amplitude.

Hierdie protokol het in totaal dus ses subtellings gelewer.

Berekening van die vergroting-verkleiningrespons

Dit was verder nodig om die verskille in die latensies en amplitudes van die $35 \mathrm{~dB}$-golf teenoor die $80 \mathrm{~dB}$-golf vir elkeen van die proefpersone te bepaal. ' $\mathrm{n}$ Eenvoudige verskiltelling is vir hierdie kortikale vergroting of verkleining gebruik naamlik:

80dB N1-latensie minus 35dB N1-latensie

80dB P2-latensie minus 35dB P2- latensie

89dB N1-P2-amplitude minus 35dB N1-P2-amplitude

In totaal het hierdie protokol dus drie saamgestelde subtellings gehad.

Hipoteses en statistiese verwerkings

Die oorkoepelende navorsingshipoteses vir die huidige studie hou verband met die navorsingsvraag en daaruitvoortspruitende doelwitte en word soos volg geformuleer:

Die vektore van gemiddeldes van die mans en dames ten opsigte van

- die tien metinge van die ouditiewe breinstamrespons (OBR) gesamentlik geneem (Hipotese1)

- die ses metinge van die ouditiewe middellatensie-respons (OMR) gesamentlik geneem (Hipotese2)

- en die drie metinge van die saamgestelde OMR-response gesamentlik geneem (Hipotese3)

- verskil statisties beduidend van mekaar.

Die gegewens vir die huidige studie is statisties verwerk deur gebruik te maak van die BMDP-program. Hotelling se $\mathrm{T}^{2}$-toets is gebruik om te bepaal of die vektore van gemiddeldes van die twee kontrasterende groepe (mans teenoor dames) statisties beduidend van mekaar verskil al dan nie. Student se t-toets en die F-toets is toegepas om verskille in gemiddeldes en variansies onderskeidelik tussen die twee groepe te toets.

\section{RESULTATE}

Die resultate van die ondersoek was soos volg:

TABeL 1

BEDUIDENHEID VAN VERSKILLE TEN OPSIGTE VAN DIE SUBTELLINGS VAN DIE OBR-METINGE TUSSEN DIE MANS EN DIE DAMES

\begin{tabular}{|c|c|c|c|c|c|c|c|c|c|c|}
\hline \multirow[t]{2}{*}{ Veranderlikes } & \multicolumn{2}{|c|}{$\begin{array}{c}\text { Mans } \\
\mathrm{N}=81\end{array}$} & \multicolumn{2}{|c|}{$\begin{array}{c}\text { Dames } \\
\mathrm{N}=210\end{array}$} & \multirow[t]{2}{*}{$\begin{array}{c}\text { Variansie } \\
\text { Verhouding }\end{array}$} & \multirow[t]{2}{*}{$\begin{array}{c}\text { Grade van } \\
\text { Vreiheid }\end{array}$} & \multirow[t]{2}{*}{$\mathbf{P}$} & \multirow[t]{2}{*}{ t-waardes } & \multirow[t]{2}{*}{$\begin{array}{l}\text { Grade van } \\
\text { Vreiheid }\end{array}$} & \multirow[t]{2}{*}{$\mathbf{P}$} \\
\hline & $\overline{\mathrm{X}}$ & SA & $\bar{X}$ & SA & & & & & & \\
\hline Golf I-latensie & 1,60 & 0,14 & 1,56 & 0,12 & 1,86 & 1,289 & 0,173 & 2,10 & 289 & $0,036^{*}$ \\
\hline Golf II-latensie & 2,71 & 0,15 & 2,65 & 0,14 & 0,23 & 1,289 & 0,630 & 3,29 & 289 & 0,001 * \\
\hline Golf III-latensie & 3,74 & 0,14 & 3,63 & 0,15 & 0,00 & 1,289 & 0,958 & 5,97 & 289 & $0,000^{*}$ \\
\hline Golf IV-latensie & 4,83 & 0,17 & 4,75 & 0,18 & 1,61 & 1,289 & 0,205 & 3,37 & 289 & 0,001 * \\
\hline Golf V-latensie & 5,58 & 0,19 & 5,44 & 0,19 & 0,18 & 1,289 & 0,674 & 5,89 & 289 & 0,000 * \\
\hline Golf I-amplitude & 0,09 & 0,07 & 0,10 & 0,10 & 4,73 & 1,289 & $0,030^{*}$ & $-0,95$ & 210.2 & 0,344 \\
\hline Golf II-amplitude & 0,05 & 0,06 & 0,06 & 0,10 & 8,52 & 1,289 & $0,004^{*}$ & $-0,61$ & 229,1 & 0,542 \\
\hline Golf III-amplitude & 0,16 & 0,09 & 0,21 & 0,12 & 2,78 & 1,289 & 0,097 & $-3,45$ & 289 & 0,001 * \\
\hline Golf IV-amplitude & 0,13 & 0,08 & 0,16 & 0,11 & 7,96 & 1,289 & $0,005^{*}$ & $-2,76$ & 206,8 & $0,006^{*}$ \\
\hline Golf V-amplitude & 0,11 & 0,08 & 0,13 & 0,12 & 10,25 & 1,289 & $0,002 *$ & $-1,22$ & 216,1 & 0,223 \\
\hline
\end{tabular}

Hotelling $\mathrm{T}^{2}=5,7776$

F-waarde $=5,4041$

$\mathrm{Gv}=10$ en 280

$\mathrm{P}=0,0001^{* *}$ 
Volgens Tabel 1 is daar statisties beduidende verskille in die vektore van gemiddeldes van die twee groepe ten opsigte van die ouditiewe breinstamresponse (Hotelling se $\mathrm{T}^{2}=0,0001$ ). Die verskille manifesteer in al die latensie-metinge (I-V) en twee van die amplitude-metinge (III en IV), waar die mans telkens langer latensies en laer amplitudes toon. Steun is dus gevind vir Hipotese 1.

Volgens Tabel 2 is daar statistiese beduidende verskille in die vektore van gemiddeldes van die twee groepe ten opsigte van die ouditiewe middellatensie -response (Hotelling se $\mathrm{T}^{2}=0,0006$ ). Die verskille manifesteer in die $35 \mathrm{~dB}$ N1-P2-amplitude en in die 80dB N1-latensie, waar die mans weer eens 'n laer amplitude en 'n langer latensie as die dames toon. Steun is dus gevind vir Hipotese 2.

Volgens Tabel 3 is daar statisties beduidende verskille in die vektore van gemiddeldes van die twee groepe ten opsigte van vergroting-verkleiningresponse (Hotelling se $T^{2}=0,0452$ ). Die verskille manifesteer egter slegs in die $80 \mathrm{~dB}$ N1-latensie minus die 35dB N1-latensie, waar sowel die mans as die dames 'n korter N1-latensie by $80 \mathrm{~dB}$ as by $35 \mathrm{~dB}$ getoon het, maar waar die mans se verskilrespons kleiner as die van die dames was. Geen verskille in die amplitude-meting het geblyk nie. Steun is gevind vir Hipotese 3.

\section{BESPREKING VAN RESULTATE}

Die resultate van die studie dui op geslagsverskille in die ouditiewe ontlokte potensiaal van die brein ten opsigte van die breinstam- en middellatensie-response. Die statisties beduidende verskil in gemiddeldes tussen die twee geslagte ten opsigte van die $80 \mathrm{~dB}$ N1-latensie minus die $35 \mathrm{~dB}$ N1-latensie is stellig ' $\mathrm{n}$ funksie van die langer N1-latensies wat in Tabel 2 ten opsigte van die mans in vergelyking met die dames gerapporteer is. Die gemiddelde konduksietyd van die dames by die $80 \mathrm{~dB}$ stimulusintensiteit was heelwat vinniger as by $35 \mathrm{~dB}$. In die afwesigheid van amplitude-verskille kan egter geen finale gevolgtrekkings oor die kortikale vergroting-verkleiningfenomeen gemaak word nie. Hierdie aspek sal gevolglik nie verder bespreek word nie.

\section{Interpretasie}

Die verklaring van die geslagsverskille in latensies en amplitudes van die ouditiewe breinstam- en middellatensieresponse lê heel moontlik by die neurale oorsprong van die onderskeie golwe. Die latensie van 'n golf verwys na die tydsinterval tussen die aanbieding van die stimulus en die vorming van 'n bepaalde golfpiek. 'n Kort latensie verwys dus na 'n vinniger konduksietyd as 'n lang latensie, moontlik as gevolg van die graad van miëlienisering. Op soortgelyke wyse verwys golfamplitude na elektro-neurofisiologiese aktiwiteit in verskillende anatomiese strukture van die brein. Meer aktiwiteit sal tot hoër amplitudes aanleiding gee. In die huidige studie was albei die geslagte se ouditiewe breinstamlatensies en -amplitudes normaal. Konduksie in die gehoorsenuwee, kogleêre nukleus, laterale lemniskus en inferior colliculus ten opsigte van die breinstamresponse (Chiappa, 1983; Davis \& Owen, 1985; Moller, Moller \& Jannetta, 1982) blyk volgens die huidige resultate egter vinniger te wees by dames as by mans, en meer senuwee-aktiwiteit word by dames as by mans in die breinstam gegenereer. Dieselfde geld ook ten opsigte van aktiwiteit in die pons, tegmentale (midbrein) en talamiese gebiede vir die middellatensie-response (Buchwald, 1990)

TABel 2

BEDUIDENHEID VAN VERSKILLE TEN OPSIGTE VAN DIE SUBTELLINGS VAN DIE OMR-METINGE TUSSEN DIE MANS EN DIE DAMES

\begin{tabular}{|c|c|c|c|c|c|c|c|c|c|c|}
\hline \multirow[t]{2}{*}{ Veranderlikes } & \multicolumn{2}{|c|}{$\begin{array}{c}\text { Mans } \\
\mathrm{N}=81\end{array}$} & \multicolumn{2}{|c|}{$\begin{array}{c}\text { Dames } \\
N=210\end{array}$} & \multirow[t]{2}{*}{$\begin{array}{c}\text { Variansie } \\
\text { Verhouding }\end{array}$} & \multirow[t]{2}{*}{$\begin{array}{c}\text { Grade van } \\
\text { Vreiheid }\end{array}$} & \multirow[t]{2}{*}{$\mathbf{P}$} & \multirow[t]{2}{*}{ t-waardes } & \multirow[t]{2}{*}{$\begin{array}{c}\text { Grade van } \\
\text { Vreiheid }\end{array}$} & \multirow[t]{2}{*}{$\mathbf{P}$} \\
\hline & $\bar{X}$ & SA & $\bar{X}$ & SA & & & & & & \\
\hline OMR 35dB N1-latensie & 97,74 & 19,61 & 98,82 & 14,57 & 2,33 & 1,289 & 0,128 & $-0,51$ & 289 & 0,611 \\
\hline OMR 35dB P2-latensie & 175,78 & 22,55 & 171,43 & 20,51 & 0,73 & 1,289 & 0,394 & 1,58 & 289 & 0,116 \\
\hline OMR 35dB N1- P2-amplitude & 2,26 & 1,58 & 3,39 & 2,45 & 17,05 & 1,289 & $0,000^{*}$ & $-4,65$ & 224,0 & $0,0000^{*}$ \\
\hline OMR 80dB N1-latensie & 95,26 & 13,22 & 89,97 & 15,40 & 0,79 & 1,289 & 0,376 & 2,73 & 289 & $0,007^{*}$ \\
\hline OMR 80dB P2-latensie & 178,16 & 28,53 & 172,75 & 23,10 & 0,77 & 1,289 & 0,380 & 1,67 & 289 & 0,095 \\
\hline OMR 80dB N1-P2-amplitude & 16,82 & 17,43 & 21,58 & 19,85 & 0,81 & 1,289 & 0,370 & $-1,90$ & 289 & 0,059 \\
\hline
\end{tabular}

Hotelling $\mathrm{T}^{2}=24,9227$

F-waarde $=4,0819$

$\mathrm{gv}=6$ en 284

$\mathrm{p}=0,0006^{* *}$

TABel 3

BEDUIDENHEID VAN VERSKILLE TEN OPSIGTE VAN DIE SUBTELLINGS VAN DIE OMR- EN P300-METINGE TUSSEN DIE MANS EN DIE DAMES

\begin{tabular}{|c|c|c|c|c|c|c|c|c|c|c|}
\hline \multirow[t]{2}{*}{ Veranderlikes } & \multicolumn{2}{|c|}{$\begin{array}{l}\text { Mans } \\
\mathrm{N}=81\end{array}$} & \multicolumn{2}{|c|}{$\begin{array}{c}\text { Dames } \\
\mathrm{N}=210\end{array}$} & \multirow[t]{2}{*}{$\begin{array}{l}\text { Variansie } \\
\text { Verhouding }\end{array}$} & \multirow[t]{2}{*}{$\begin{array}{c}\text { Grade van } \\
\text { Vreiheid }\end{array}$} & \multirow[t]{2}{*}{$\mathbf{P}$} & \multirow[t]{2}{*}{ t-waardes } & \multirow[t]{2}{*}{$\begin{array}{c}\text { Grade van } \\
\text { Vreiheid }\end{array}$} & \multirow[t]{2}{*}{$\mathbf{P}$} \\
\hline & $\bar{X}$ & SA & $\bar{X}$ & SA & & & & & & \\
\hline $\begin{array}{l}\text { 80dB N1-latensie minus } \\
\text { 35dB N1-latensie }\end{array}$ & $-1,94$ & 22,45 & $-8,85$ & 19,86 & 1,08 & 1,289 & 0,376 & 2,73 & 289 & 0,011 * \\
\hline $\begin{array}{l}\text { 80dB P2-latensieminus } \\
\text { 35dB P2-latensie }\end{array}$ & 3,89 & 38,15 & 1,32 & 30,01 & 4,60 & 1,289 & 0,380 & 1,67 & 120,1 & 0,587 \\
\hline $\begin{array}{l}\text { 80dB N1-P2-amplitude minus } \\
\text { 35dB N1-P2-amplitude }\end{array}$ & 14,56 & 16,24 & 18,19 & 18,29 & 0,61 & 1,289 & 0,370 & $-1,90$ & 289 & 0,119 \\
\hline
\end{tabular}


naamlik dat dames se responslatensies vinniger is en die amplitudes hoër pieke het. Churchland (1986) verduidelik geslagsverskille in brein-funksionering aan die hand van prenatale testosteroon-invloede. Die fetale testosteroon-vlakke is veral gekonsentreerd in die hipotalamus, amigdala, midbrein en pre-optiese gebiede. Dit is hierdie gebiede wat hoofsaaklik betrokke is by die generasie van sekere ontloktepotensiaalkomponente.

Volgens die literatuur reflekteer die neurofisiologiese aktiwiteit in die gehoorsenuwee, kogleêre nukleus, laterale lemniskus en inferior colliculus, soos gemeet deur die ontlokte breinstamrespons, en in die pons, tegmentale (midbrein) en talamiese gebiede soos gemeet deur die middellatensie-respons, die neurologiese integriteit al dan nie van die onderhawige breingebiede. Volgens die literatuur reflekteer dit egter ook die vroegste neurofisiologiese uitdrukking van temperament. So byvoorbeeld het Stelmack en Wilson (1982) en Woodward et al. (2001) met verwysing na die ouditiewe breinstampotensiaal, en Stelmack en MichaudAchorn (1985) met verwysing na die middellatensierespons, gevind dat introverte korter latensies as ekstroverte demonstreer. Ten opsigte van disinhibisie as temperamentstrek het Steinberg, Rosen en Risberg (1988) met behulp van visuele ontlokte potensiaal kortikale vergrotingsresponse gedemonstreer.

Aangesien dit bekend is dat daar geslagsverskille in sekere temperamentsdimensies voorkom (byvoorbeeld sosiale ekstroversie en sensasiesoeke (Berenbaum \& Hines, 1992; Gleason, Gower \& Hohmann, 2005; Stuart, 1994)), volg dit dat geslagsverskille ook in die neurologiese aktiwiteit en konduksietyd van die genoemde breingebiede verwag kan word. In die geval van temperament word geslag as veranderlike in die meeste navorsingstudies verantwoord. In die geval van die ontlokte potensiaal van die brein word hierdie aspek merendeels geïgnoreer, met die uitsondering van enkele studies soos in die literatuuroorsig aangedui. Die huidige studie het daarin geslaag om geslagsverskille in robuuste en verifieerbare ontlokte golfvorms te demonstreer. Die afleiding word gemaak dat die ouditiewe sensoriese sisteem en sentrale breingebiede ook deur geslagsverskille gekenmerk word en dat die neurofisiologiese verankering van temperament moontlik reeds in die breinstamen midbreingebiede voorkom. Ontologies is hierdie breingebiede die vroegste fetale neurologiese strukture wat ontwikkel en vorm dit die essensiële breinstrukture van die meeste diere.

\section{Gevolgtrekkings en waarde}

Die huidige studie het empiries kon aandui dat daar geslagsverskille in die ouditiewe breinstam- en middellatensieontloktepotensiaal van die brein voorkom. In ontloktepotensiaal-studies, hetsy vir oudiologiese/optalmologiese doeleindes of vir gedragstudies, behoort geslag as veranderlike dus verreken te word.

'n Verdere gevolgtrekking is dat daar ook geslagsverskille is in die aktiwiteitsvlakke van die generatorgebiede van die gemelde ontlokte potensiaal van die brein. Die bevestiging van geslagsverskille in die generatorgebiede benodig verdere empiriese studies met onder andere ook skanderingsmetodologie.

'n Verdere gevolgtrekking wat uit die bevindinge van die huidige studie spruit is dat ten minste sekere temperamentsdimensies se vroegste neurofisiologiese verankering moontlik reeds in die fetale ontwikkelingstadia voorkom, waar inter alia differensiële werking van die gonodale hormone die brein se ontwikkeling stu. Dit is dus moontlik dat byvoorbeeld mans met hoë versus lae testosteroonvlakke ook verskille in ontloktepotensiaal- response sou toon. Sodanige navorsing sou die gevolgtrekkinge van die huidige studie empiries kon steun.

Die studie kon geen gevolgtrekking rakende die kortikale vergroting-verkleiningrespons maak nie en verdere navorsing word in hierdie opsig benodig.

Toenemend word die neurologiese en fisiologiese aktiwiteite wat gepaard gaan met temperamentuitdrukking deur navorsing ontbloot. 'n Individu se werkstyl as uitdrukking van temperament (Eliasz, 1985) beskerm hom/haar teen uitputting en oormatige spanning. Wanneer ' $n$ werknemer nie die geleentheid het om te kompenseer vir spanning deur 'n geïndividualiseerde werkstyl te handhaaf nie, is daar psigofisiologiese nagevolge wat nie alleenlik vir die individu nie, maar ook vir die maatskappy tot nadeel strek. Eliasz (1985) sê in hierdie verband die volgende: "Certainly, when it comes to jobs, a person will not always make a good choice with respect to stimulation requirement. Moreover, in case of bad choice, the person may not quit the job soon enough because of his involvement in the job, high wages, or some other reason. Nevertheless, the employee may still be removed because of deteriorating health and frequent absences, lower efficiency in comparison with othe employees, and injuries at work" (p47). Halmiova en Sebova (1986, p 127) sê ook in hierdie verband: "The effect of properties of the nervous system appears to be of significance in various types of activities - in learning, work, sports activity, as well as in tasks designed to explore basic mental processes, for instance memory, thinking, and motivation" . Die daarstelling van 'n psigofisiologies-gebaseerde sisteem van personeelkeuring-en plasing is nie uitgesluit vir die toekoms nie.

Afgesien van die belang van die huidige studie vir die werksmilieu, kan 'n begrip van die omvang en diepte van die fisiologiese en neurologiese wortels van menslike gedrag ook waardevol wees in onder andere die kliniese milieu, waar reeds sterk neurofisiologiese modelle vir die verklaring van psigologiese disfunksie bestaan, en ook in die opvoedkundige milieu, waar dit reeds bekend is dat 'n leerder se keuse van studiemetodes onder andere geassosieer word met temperament.

\section{Tekortkominge en aanbevelings vir verdere navorsing}

In die huidige studie is met sorg verseker dat steuringsveranderlikes nie die resultate kontamineer nie. Die proefpersone is versigtig gekies, die ontloktepotensiaalprosedures is nougeset toegepas en die laboratoriumtoestande goed gekontroleer. Dit is egter nie moontlik om alle veranderlikes te kontroleer nie. Dit is moontlik dat verskillende persone verskillend op die metingsomstandighede reageer wat steuringsveranderlikes soos angs produseer. Die ontloktepotensiaal-metinge kan hierdeur geaffekteer word.

Hemisferiese asimmetrie is nie in ag geneem nie en sou interessante toekomstige navorsing kon wees.

In die huidige studie is spesifiek op die ouditiewe bane gefokus en toekomstige studies behoort ook die visuele en somatosensoriese bane te ondersoek.

Die huidige studie het die aktiewe elektrode op $\mathrm{Cz}$ geplaas met verwysings na M1 en Fpz. Meervoudige elektrodeplasings sou alternatiewe en/of bevestigende bevindinge kon produseer, veral met verwysing na die frontale en temporale gebiede.

Die universum vir die huidige studie het uit studente in die gedragswetenskappe bestaan en bevindinge kan nie sonder meer na ander universums veralgemeen word nie. Steekproewe uit 
ander kultuurgroepe, ouderdomsgroepe en studierigtings sou grootliks kon bydra tot die bevestiging en uitbreiding van kennis ten opsigte van die ontlokte potensiaal van die brein en temperamentsteorieë.

"As long as our brain is a mystery, the universe - the reflection of the structure of the brain - will also be a mystery". Santiago Ramón y Caja, ca. 1898

\section{BRONNELYS}

Bar-Haim, Y. (2003). Mismatch negativity in socially withdrawn children. Biological Psychiatry, 54 (1), 17-24.

Bars, D.R. (2001). Use of visual evoked-potential studies and EEG data to classify aggressive, explosive behavior of youths. Psychiatric Services, 52 (1), 81-6.

Benenson, J. (1993). Greater preferences among females than males for dyadic interaction in early childhood. Child Development, 64, 544-555.

Berenbaum, S., \& Hines, M. (1992). Early androgens are related to childhood sex-typed toy preferences. Psychological Science, 3, 203-206.

Buchsbaum, M.S., Henkin, R.I., \& Christiansen, R.L. (1974). Age and sex differences in averaged evoked responses in a normal population with observations of patients with gonadal dysgenesis. Electroencephalography and Clin. Neurophysiology, 37, 137-144.

Buchwald, J.S. (1990). Animal models of cognitive eventrelated ptentials. In J.W Rohrbaugh, R. Parasuraman \& R. Johnson, Jr. (Eds), Event-related brain potentials - Basic issues and applications. New York: Oxford University Press.

Bullock, W.A., \& Gilliland, K. (1993). Eysenck's arousal theory of introversion-extraversion: A converging measures investigation. J. Pers. Soc. Psychol., 64 (1), 113-123.

Campbell, K.B., Baribeau-Brown, J., \& Braun, C. (1981). Neuroanatomical and physiological foundations of extraversion. Psychophysiology, 18, 263-267.

Carillo-de-la-Pena, M.T. (1992). ERP augmenting/reducing and sensation seeking: critical review. International Journal of Psychophysiology, 12 (3), 211-220.

Chiappa, K.H. (1983). Evoked potentials in clinical medicine. New York: Raven Press.

Churchland, P.S. (1986). Neurophilosophy: Toward a unified science of the mind-brain. Cambridge: Bradford

Connolly, J.F. (1986). Evoked potential augmenting-reducing: A weak link in the biology-personality chain. Behav. Brain Sci., 9, 746-747.

Connolly, J.F., \& Gruzelier, J.H. (1982). Amplitude and latency changes in the visual evoked potential to different stimulus intensities. Psychophysiology, 19, 599-608.

Davis, H., \& Owen, J.H. (1985). Brainstem auditory evoked responses. In H. Davis \& J.H. Owen (Eds) Evoked potential testing - Clinical applications. New York: Grunl \& Stratton.

Dehan, C.P. \& Jerger, J. (1990). Analysis of gender differences in the auditory brainstem response. Laryngoscope, 100 (1), $18-24$.

Dragatinovich, S. (1987). Stimulus intensity reducer: Are they sensation seekers, extraverts, and strong nervous types? Personality and Individual Differences, 8 (5), 693-704.

Eliasz, A. (1985). Mechanisms of temperament: Basic functions. In J. Strelau, F.H. Farley \& A. Gale (Eds), The biological basis of of personality and behaviour: Theories, measurement techniques, and development. New York: Hemisphere.

Fallgatter, A.J. (1998). Event-related correlates of response suppression as indicators of novelty seeking in alcoholics. Alcohol and Alcoholism, 33 (5), 475-81.

Fein, G. \& Brown, F.F. (1987). Gender differences in pattern reversal evoked potentials in normal elderly. Psychophysiology, 24 (6), 683-690.
Gershon, E.S., \& Buchsbaum, M.S. (1977). A genetic study of average evoked response: augmentation-reduction in affective disorders. In C. Shagass \& A.J. Friedholf (Eds), Psychopathology and brain disfunction. New York: Raven Press.

Gleason, T.R., Gower, A.L., Hohmann, L.M., \& Gleason, T.C. (2005). Temperament and friendship in preschool-aged children. International Journal of Behavioral Development, 29, 336-344.

Halmiova, O. \& Sebova, E. (1986). Nervous system propertiesand coding processes. In J. Strelau, F.H. Farley \& A. Gale (Eds). The biological basis of personality and behaviour: Psychophysiology, performance and applications. New York: Hemisphere.

Hannay, H.J. (1986). Experimental technique in human neuropsychology. New York: Oxford University Press.

Hegerl, U., Prochno, I., Ulrich, G., \& Muller-Oerlinghausen, B. (1989). Sensation seeking and auditory evoked potentials. Biological Psychiatry, 25 (2), 179-190.

Herrmann, M.J. (2002). Electrophysiological indication for a link between serotonergic neurotransmission and personality in alcoholism. Progress In Neuro-Psychopharmacology \& Biological Psychiatry, 26 (1), 157-61.

Jasper, H.H. (1958). The ten twenty electrode system of the International Federation. Electroencephalography and Clinical Neurophysiology, 10, 371-375.

Loveless, N.E. (1983). Event-related brain potentials and Human Performance. In A. Gale and J.A. Edwards (Eds), Physiological correlates of human behaviour, Volume II: Attention and performance. London: Academic Press.

Michalewski, H.J., Thompson, L.W., Patterson, J.V., Bowman, J.E., \& Litzelman, D. (1980). Sex differences in the amplitudes and latencies of the human auditory brain stem potential. Electroencephalogr. Clin. Neurophysiol., 48, 351-356.

Moller, M.B., Moller, A.R., \& Jannetta, P.J. (1982). Brainstem auditory evoked potentials in patients with hemifacial spasm. Laryngoscope, 92, 848-852.

Robinson, D.L. (2001). How brain arousal systems determine different temperament types and the major dimensions of personality. Personality and Individual Differences, 31, 1233-1259

Rothbart, M., Ahadi, S., \& Evans, D. (2000). Temperament and personality: Origins and early childhood. Child Development, 64, 544-555.

Saxton, P.M., Siegel, J. \& Lukas, J.H. (1987). Visual evoked potential augmenting/reducing slopes in cats- 2 . Correlations with behavior. Personality and Individual Differences, 8, 511-519.

Sermat, V., \& Smyth, M. (1973). Content analysis of verbal communication in the development of a relationship: Conditions influencing self-disclosure. Journal of Personality and Social Psychology, 26, 332-347.

Shearer, D.E., Emmerson, R.Y., \& Dustman, R.E. (1992). Gender differences in pattern reversal evoked potential amplitude: Influence of check size and single trial response variability. American Journal of EEG Technology, 32 (3), 196-203.

Steinberg, G., Rosen, I., \& Risberg, J. (1988). Personality and augmenting/reducing in visual and auditory evoked potentials. Personality and Individual Differences, 9 (3), 571 579 .

Stelmack, R.M., \& Michaud-Achorn, A. (1985). Extraversion, attention, and habituation of the auditory evoked response. Journal of Research in Personality, 19 (4), 416-428.

Stelmack, R. M., \& Wilson, K. G.,(1982). Extraversion and the effects of frequency and intensity of the auditory brainstem response. Personality an Individual Differences, 3, 373-380.

Stuart, A.D. (1994). Die ontlokte potensiaal van die brein en sekere temperamentdimensies. Ongepubliseerde doktorale proefskrif. Randse Afrikaanse Universiteit.

Sturzebecher, E., \& Werbs, M. (1987). Effects of age and sex on auditory brain stem response: A new aspect. Scandinavian Audiology, 16 (3), 153-157. 
Torgensen, A.M. (1985). Temperamental differences in infants and 6-year old children: a follow-up study of twins. In J. Strelau, F.H. Farley, \& A. Gale (Eds), The biological basis of personality and behavior: Theories, measurement, techniques, and development. Washington, D.C.: Hemisphere.

Von Knorring, L. (1981). Visual evoked responses and platelet monoamine oxidase in patients suffering from alcoholism. In H. Begleiter (Ed), The biological effect of alcohol (pp. 270291). New York: Plenum Press.
Woodward, S.A., \& McManis, M.H., Kagan, J., \& Deldin, P. Snidman, N., Lewis, M., \& Kahn, V. (2001). Infant temperament and the brainstem auditory evoked response in later childhood. Dev Psychol, 37 (4) 533-8.

Zuckerman, M. (1990). The psychophysiology of sensation seeking. Journal of Personality, 58, 313-345.

Zuckerman, M. (1991). Problems in the behavioural sciences. Psychobiology of personality. Cambridge: Cambridge University Press.

Zuckerman, M. (2005). Psychobiology of Personality. Cambridge University Press. 